\title{
The composition of government spending and the multiplier at the Zero Lower Bound
}

\author{
Julien Albertini* \\ Arthur Poirier** \\ Jordan Roulleau-Pasdeloup***
}

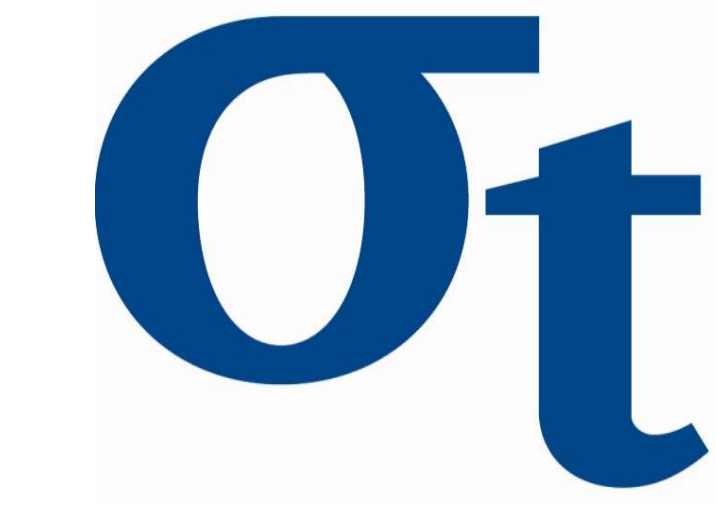

$\underline{v}$

* Humboldt-Universität zu Berlin, Germany

** University of Evry-Val-d'Essonne, France $* * *$ CREST, PSE, France

This research was supported by the Deutsche Forschungsgemeinschaft through the SFB 649 "Economic Risk".

http://sfb649. wiwi.hu-berlin.de ISSN 1860-5664 


\title{
The composition of government spending and the multiplier at the Zero Lower Bound
}

\author{
Julien Albertini* \\ INSTITUTE FOR ECONOMIC THEORY II \\ Humboldt-Universität zu Berlin \\ Spandauerstraße 1 \\ 10178 Berlin \\ Arthur Poirier ${ }^{\dagger}$ \\ EPEE, TEPP \\ University of Evry-Val-d'Essonne \\ Bd, François Mitterand \\ 91025 Evry Cedex \\ Jordan Roulleau-Pasdeloup ${ }^{\ddagger}$ \\ CREST, PSE \\ 15 Boulevard Gabriel Peri \\ 92245 Malakoff Cedex \\ February 15, 2014
}

\begin{abstract}
We investigate the size of the multiplier at the ZLB in a New keynesian model. It ranges from around -0.25 to +1.5 , depending on the extent to which government spending is productive, substitutable or not for private consumption.
\end{abstract}

Keywords: Zero lower bound, New Keynesian, Government spending multiplier.

JEL Classification: E31, E32, E52, E62

Acknowledgment We thank Xavier Fairise for his helpful comments. Any errors and omissions are ours. This research was supported by the Deutsche Forschungsgemeinschaft through the SFB 649 "Economic Risk".

\footnotetext{
*Corresponding author. Email address: albertij@cms.hu-berlin.de, Tel. : $+493020935710$

${ }^{\dagger}$ Email address: arthur .poirier@univ-evry .fr, Tel. : +33169477186

‡Email address: jordan.roulleau-pasdeloup@ensae.fr, Tel. : +33141177792
} 


\section{Introduction}

The size of the multiplier has received a renewed interest since the American Investment and Reinvestment Act (ARRA) stimulus has been enacted in 2009. Influential papers in the recent New Keynesian literature have shown that the government spending multiplier is larger at the zero lower bound (ZLB for short) on the nominal interest rate than in normal times (Eggertsson (2011), Christiano et al. (2011) and Fernández-Villaverde et al. (2012)). The reason is that when the nominal interest rate is pinned at zero, the monetary policy does not absorb the propagation of the government spending shock which better translates into output. However, these studies have paid little attention to the way government spending is modeled while the composition of the fiscal package may crucially impact the size of the multiplier. The ability of government spending to serve as input to private production or to be substitutable for private consumption (Barro (1990)) may have important consequences.

In a simple New Keynesian model, we investigate alternative specifications for the composition of government spending. We show that the multiplier at the ZLB is 1) lower when the government spending is productive; 2) lower when consumption and government purchases are substitutable and 3) negative if the composition of the fiscal package rules out the non substitutability of government spending for private consumption. With our preferred ARRA specification the multiplier is barely higher than outside the ZLB and lower than 1.

\section{The model}

We build a standard New Keynesian DSGE model with Rotemberg sticky prices, monopolistic competition and a Taylor rule on the nominal interest rate. Government spending can be either productive $\left(G_{t}^{p}\right)$ or utility-enhancing. The second case can be divided into perfectly substitutable $\left(G_{t}^{S}\right)$ and non-substitutable $\left(G_{t}^{n}\right)$ for private consumption.

\subsection{The representative household}

Households intertemporal utility is defined by:

$$
\max _{c_{t}, d_{t}, n_{t}} E_{0} \sum_{t=0}^{\infty}\left(\prod_{k=0}^{t} \beta_{k}\right)\left[\frac{\left(c_{t}+G_{t}^{s}\right)^{1-\sigma}}{1-\sigma}-\ell \frac{n_{t}{ }^{1+\phi}}{1+\phi}+\frac{\left(G_{t}^{n}\right)^{1-\sigma}}{1-\sigma}\right]
$$

where $c_{t}$ is aggregate consumption and $n_{t}$ is the level of employment supplied by households. $\sigma$ and $\phi$ denote the risk aversion coefficient and the inverse of 
the Frisch elasticity respectively. $\beta_{t}$ represents a discount factor shock that we interpret as a preference shock. The representative household takes as given $\left\{p_{t}, w_{t}, i_{t}\right\}_{t=0}^{\infty}$ and the initial wealth $\left(d_{0}\right)$ in order to maximize equation (1) subject to the budget constraint:

$$
p_{t} c_{t}+d_{t}=d_{t-1}\left(1+i_{t-1}\right)+w_{t} n_{t}+\Pi_{t}-T_{t}
$$

where $\Pi_{t}$ is firms' profits, $d_{t}$ bonds, $p_{t}$ the aggregate price and $T_{t}$ is a lumpsum tax. Optimality conditions are given by the following equations (with $\pi_{t}=p_{t} / p_{t-1}$ and $\left.w_{t}^{R}=w_{t} / p_{t}\right)$ :

$$
\begin{aligned}
\lambda_{t} & =\left(c_{t}+G_{t}^{s}\right)^{-\sigma} \\
\lambda_{t} & =\left(1+i_{t}\right) E_{t} \beta_{t+1} \frac{\lambda_{t+1}}{\pi_{t+1}} \\
w_{t}^{R} & =\ell n_{t}^{\phi}\left(c_{t}+G_{t}^{s}\right)^{\sigma}
\end{aligned}
$$

\subsection{Firms}

The final good producer operates in a perfectly competitive market. He produces a good $y_{t}$ using intermediate goods $y_{j t}$. The demand for the intermediate good $j$ writes:

$$
y_{j t}=\left(\frac{p_{j t}}{p_{t}}\right)^{-\epsilon} y_{t}
$$

where $\epsilon$ is the elasticity of substitution between goods. The nominal price index is defined by $p_{t}=\left[\int_{0}^{1} p_{j t}^{1-\epsilon} d j\right]^{\frac{1}{1-\epsilon}}$.

There is a continuum of monopolistically competitive producers indexed by $j$ using two inputs to produce and sell output $y_{j t}$ to final good producers. The first one is labor $n_{j t}$ (such that $n_{t}=\int_{0}^{1} n_{j t} d j$ ). As in Linnemann \& Schabert (2006), Bouakez \& Guillard (2013) and Roulleau-Pasdeloup (2013), the second one is productive government spending $G_{t}^{p}$ :

$$
y_{j t}=\left(G_{t}^{p}\right)^{1-\alpha} n_{j t}^{\alpha}
$$

with $1-\alpha$ being the elasticity of output to productive government spending. We thus make the standard assumption of constant returns to scale. Firm $j$ maximizes its intertemporal profit (8) taking $\left\{p_{t}, w_{t}\right\}_{t=0}^{\infty}$ as given, subject to (6) and (7):

$$
\max _{p_{j t}, n_{j t}} E_{0} \sum_{t=0}^{\infty}\left(\prod_{k=0}^{t} \beta_{k}\right) \frac{\lambda_{t}}{\lambda_{0}}\left[\frac{p_{j t}}{p_{t}} y_{j t}-\frac{w_{t}}{p_{t}} n_{j t}-y_{t} \frac{\psi}{2}\left(\frac{p_{j t}}{\pi p_{j t-1}}-1\right)^{2}\right]
$$


The price adjustment cost-governed by $\psi$-is proportional to output and $\pi$ is the steady state gross inflation rate. Dropping subscript $j$ by symmetry, the optimality conditions are:

$$
\begin{aligned}
m c_{t} & =w_{t}^{R} \frac{n_{t}}{\alpha y_{t}} \\
0 & =(1-\epsilon)+\epsilon m c_{t}-\psi \frac{\pi_{t}}{\pi}\left(\frac{\pi_{t}}{\pi}-1\right) \\
& +E_{t} \beta_{t+1} \frac{\lambda_{t+1}}{\lambda_{t}} \psi \frac{\pi_{t+1}}{\pi}\left(\frac{\pi_{t+1}}{\pi}-1\right) \frac{y_{t+1}}{y_{t}}
\end{aligned}
$$

where $m c_{t}$ is the Lagrange multiplier associated with (7). Equation (10) is the forward-looking New Keynesian Phillips Curve.

\subsection{Monetary and fiscal authorities}

We assume that the central bank adjusts the nominal interest rate following a Taylor rule ${ }^{1}$ (bounded by the ZLB) in response to deviations of inflation and output from their steady-state values:

$$
1+i_{t}= \begin{cases}\frac{\pi}{\beta}\left(\frac{\pi_{t}}{\pi}\right)^{\rho_{\pi}}\left(\frac{y_{t}}{y}\right)^{\rho_{y}} & \text { if } \quad i_{t}>0 \\ 1 & \text { otherwise }\end{cases}
$$

Total government expenditures $G_{t}$ are shared as follows: $G_{t}^{s}=\tau G_{t}, G_{t}^{p}=\gamma G_{t}$ and $G_{t}^{n}=(1-\tau-\gamma) G_{t}$, with $0 \leq \tau+\gamma \leq 1$. Finally, $G_{t}=\bar{g} \exp \left(g_{t}\right)$ where $g_{t}$ follows an $\mathrm{AR}(1)$ process and $\bar{g}$ is the amount of government spending at the steady state.

\subsection{Market clearing}

The aggregation of individual profits $\Pi_{t}$ is given by: $\Pi_{t}=p_{t} y_{t}-n_{t} w_{t}-$ $p_{t} y_{t} \Gamma_{t}^{\pi}$. Together with the budget constraint (2) and the government budget constraint, this gives the aggregate resource constraint :

$$
y_{t}\left[1-\frac{\psi}{2}\left(\frac{\pi_{t}}{\pi}-1\right)^{2}\right]=c_{t}+G_{t}
$$

\footnotetext{
${ }^{1}$ As in Christiano et al. (2011), the interest rate has no persistence.
} 


\section{Model solution and baseline calibration}

We follow Fernández-Villaverde et al. (2012) to calibrate the model based on quarterly frequencies ${ }^{2}$.

Table 1: Parameters

\begin{tabular}{lccc}
\hline \multicolumn{1}{c}{ Variables } & Symbol & Value & Source \\
\hline Discount factor & $\beta$ & 0.994 & Standard \\
Risk aversion coefficient & $\sigma$ & 1 & Standard \\
Elast. of subst. between goods & $\epsilon$ & 6 & Standard \\
Frisch elasticity & $\phi$ & 1 & Standard \\
Annual steady state inflation & $\pi$ & 0.02 & Data \\
Production function elasticity & $\alpha$ & 0.92 & Roulleau-Pasdeloup (2013) \\
Autocorrelation coefficient & $\rho_{\beta}$ & 0.8 & Christiano et al. (2011) \\
Std. of $\beta$ shock & $\sigma_{\beta}$ & 0.002 & target 5\% at the ZLB \\
Price adjustment & $\psi$ & 40 & Standard \\
Response to inflation & $\rho_{\pi}$ & 1.5 & Standard \\
Response to output & $\rho_{y}$ & 0.25 & Standard \\
Government spending & $\bar{g}$ & 0.1815 & Target 0.2y \\
Autocorr. coefficient $g_{t}$ & $\rho_{g}$ & 0.7 & Target ARRA \\
Std. of $g_{t}$ shock & $\sigma_{g}$ & 0.1825 & Target ARRA \\
\hline
\end{tabular}

${ }^{a}$ In the log-linearized Phillips curve, $\frac{\partial \hat{\pi}_{t}}{\partial \hat{c}_{c_{t}}}=(\epsilon-1) / \psi$. Structural estimates of New Keynesian models find values around 0.5 for this coefficient (see Krause \& Lubik (2007) and the references therein), implying $\psi \simeq 10$. On the other hand, a Calvo parameter of 0.75 implies $\psi \simeq 90$. We choose an intermediate value of 40 to match the response of inflation (and thus the one of private consumption) usually obtained in the literature.

\section{Results}

We study five specifications: (i) $G_{t}=G_{t}^{n}$; (ii) $G_{t}=G_{t}^{p}$; (iii) $G_{t}=G_{t}^{s}$ and (iv) two specifications that attempt to represent the legislated part of the ARRA fiscal package. Cogan et al. (2010) have studied the impact of the ARRA but they do not provide a detailed decomposition of different types of government

\footnotetext{
${ }^{2}$ We solve the model using the Parameterized expectation algorithm (PEA) projection method. This latter solves non-linear stochastic dynamic problems using polynomials (we rely on Chebyshev ones here) to approximate conditional expectations. The probability of entering and leaving the ZLB are endogenously determined and are considered in agents' expectations. Contrary to backward-induction methods (perfect foresight and the extended path method), agents internalize future shock uncertainty since they are evaluated in the expectations. Further details are provided in the online appendix : https://sites.google. com/site/ecojulien/working-paper.
} 
spending. We therefore rely on the following table, based on BEA data, to calibrate the different shares of government spending:

\begin{tabular}{|c|c|c|c|c|c|c|c|c|c|c|c|}
\hline & 2009Q1 & 2009Q2 & 2009Q3 & 2009Q4 & 2010Q1 & 2010Q2 & 2010Q3 & 2010Q4 & 2009 & 2010 & $2009-10$ \\
\hline Total Stimulus & 0 & 89 & 118 & 135 & 142 & 132 & 116 & 94 & 341 & 484 & 825 \\
\hline Government Spending & 0 & 39 & 58 & 79 & 96 & 105 & 98 & 76 & 175 & 375 & 550 \\
\hline Income Support & 0 & 10 & 15 & 19 & 19 & 16 & 13 & 10 & 44 & 58 & 102 \\
\hline Unemployment Insurance Benefits & 0 & 4 & 6 & 8 & 8 & 7 & 6 & 4 & 18 & 25 & 43 \\
\hline Food Stamps & 0 & 2 & 3 & 4 & 4 & 3 & 2 & 2 & 9 & 11 & 20 \\
\hline COBRA Healthcare & 0 & 4 & 6 & 7 & 7 & 6 & 5 & 4 & 17 & 22 & 39 \\
\hline Infrastructure Spending & 0 & 1 & 6 & 16 & 29 & 41 & 41 & 27 & 22 & 136 & 159 \\
\hline Traditional Infrastructure & 0 & 0 & 2 & 9 & 16 & 24 & 24 & 14 & 11 & 78 & 89 \\
\hline Non-Traditional Infrastructure & 0 & 1 & 4 & 7 & 13 & 17 & 17 & 13 & 12 & 58 & 70 \\
\hline Aid to State Government & 0 & 24 & 28 & 32 & 35 & 35 & 31 & 29 & 84 & 128 & 211 \\
\hline Medicinal Match & 0 & 10 & 12 & 13 & 13 & 13 & 13 & 13 & 35 & 52 & 87 \\
\hline Fiscal Relief & 0 & 10 & 10 & 12 & 14 & 14 & 10 & 9 & 32 & 47 & 79 \\
\hline Local School District & 0 & 3 & 5 & 6 & 7 & 7 & 7 & 6 & 14 & 27 & 41 \\
\hline Law Enforcement & 0 & 1 & 1 & 1 & 1 & 1 & 1 & 1 & 2 & 2 & 4 \\
\hline Healthcare/Education /Other & 0 & 5 & 9 & 13 & 14 & 14 & 14 & 11 & 26 & 53 & 79 \\
\hline Tax Cuts & 0 & 50 & 60 & 56 & 46 & 27 & 18 & 18 & 166 & 109 & 275 \\
\hline Business Tax Benefits & 0 & 10 & 20 & 40 & 30 & 10 & 0 & 0 & 70 & 40 & 110 \\
\hline Individual Tax Benefits & 0 & 40 & 40 & 16 & 16 & 17 & 18 & 18 & 96 & 69 & 165 \\
\hline
\end{tabular}

Table 2: Composition Of THE ARRA. Source: BEA, BLS and Moody's Economy.com. In Billion dollars

When computing total government spending over 2009-2010 we do not consider income support and tax cuts since those two components are neutral in a representative agent framework with lump-sum taxes. Identifying productive government spending with infrastructure spending, we get $\gamma=$ 0.35 . The categorization of the remaining expenses is more debatable. In our preferred ARRA specification, we take the Health/Education component as perfectly substitutable government spending. This is only an approximation since, for example, public and private education differ in terms of quality. With this in mind, we find $\tau=0.18$ for the share of substitutable government spending in the stimulus plan. The remaining share is non-substitutable government spending, $1-\tau-\gamma=0.47$. However, to get a range for the multiplier under the ARRA specification, it is useful to consider two polar cases in which non-productive government spending is either non-substitutable (ARRA1) or substitutable with private consumption (ARRA2).

Finally, we choose the standard deviation and autoregressive parameters to match the size of the fiscal package as a share of GDP for 2009-2010, which is equal to $1.58 \%$. This gives $\sigma_{b}=0.1825$. We choose $\rho_{g}=0.7$ so that stimulus spending essentially vanishes after 8 quarters $^{3}$. To investigate the ZLB we use a discount factor shock $\beta_{t}$ that sends the economy in a liquidity trap 8 quarters. The multiplier at the ZLB is calculated as the response of output following a shock on $\beta_{t}$ and $g_{t}$ in deviation from the response of output to a shock on $\beta_{t}$

\footnotetext{
${ }^{3}$ Using the AR(1) process for government spending, we get that $\log \left(g_{t+8}\right)=\rho_{g}^{8}$. $\log \left(\sigma_{g} \epsilon^{\mathcal{g}}\right) \simeq 0.05 \cdot \log \left(\sigma_{g} \epsilon^{\mathcal{g}}\right)$.
} 
only ${ }^{4}$ and divided by the initial increase of $G_{t}$. The results are shown in Figure 1:
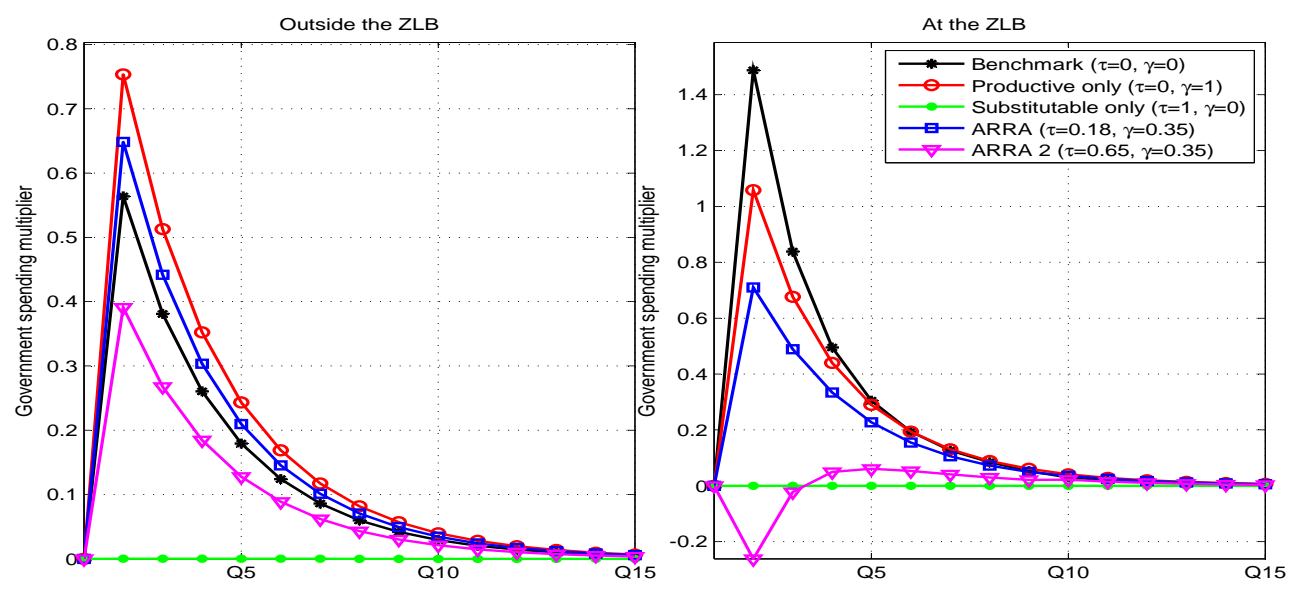

Figure 1: Government spending multiplier.

In the benchmark model, the multiplier reaches 0.56 outside the ZLB and 1.5 at the ZLB. These values are broadly consistent with the related literature in which the multiplier at the ZLB is higher than one and about three times higher than in normal times. In normal times, the nominal interest rate adjusts upward against the output and inflationary pressures caused by the increase in government purchases. Consequently, the increase in the real interest rate dampens the output effects of government expenses. When the nominal interest rate is pinned at zero, higher government spending results in a lower real rate and thus a multiplier that exceeds unity.

One can see that the composition of the fiscal package greatly influences its efficacy. One earlier reference to the composition of the fiscal package is Eggertsson (2011). He notes that for government spending to be effective at increasing demand at the ZLB, it has to be directed at goods that are imperfect substitutes with private consumption (such as infrastructure or military spending). In fact, as the dotted line shows, the impact of perfectly substitutable government spending is nil. The reason is that private consumption exactly offsets any effect stemming from this kind of government spending. However, Eggertsson (2011) treats infrastructure spending as imperfectly substitutable. Being productive, infrastructure spending should appear in the aggregate production function, implying a negative effect on the real marginal cost and thus on prices. This deflation generates higher real interest rates which reduce private consumption now. Indeed, Figure 1 shows that intro-

\footnotetext{
${ }^{4}$ See the online appendix and Fernández-Villaverde et al. (2012). The implied ZLB duration following the shock on $\beta_{t}$ and $g_{t}$ is 7 quarters. With a shock on $\beta_{t}$ only the ZLB spell is 8 quarters in the baseline.
} 
ducing productive government spending in the fiscal package can reduce the size of the output multiplier in a liquidity trap (see Bouakez \& Guillard (2013), Roulleau-Pasdeloup (2013)). Let us begin with the second polar case, ARRA2. In this case, productive government spending generates a deflation that triggers a negative multiplier at the ZLB. To paraphrase Eggertsson (2011), a policy that increases the natural rate of output can decrease actual output in the short-run. But those effects on natural output grow as $\gamma$ increases. To see this, consider the case of only productive government spending (circled line). In the short run, government spending has aggregate demand (through the product market equilibrium) as well as aggregate supply (through the production function) effects. But increasing productive government spending raises the natural level of private consumption tomorrow, which prompts households to consume more today, generating inflation today. As $\gamma$ grows larger then, increasing productive government spending is effectively an aggregate demand policy. This is why the all-productive and first polar / ARRA1 cases yield very similar results (which we do not report for the ARRA1 to save space on the graph): beyond $\gamma=0.35$, productive and non-substitutable government spending have similar effects. For our preferred ARRA specification (squared line), the aggregate demand effects of non-substitutable government spending are dampened by the aggregate supply effects of productive government spending and the nil effect coming from substitutable government spending. This results in a multiplier that hovers around 0.7 , only slightly higher from its value in normal times.

Since the Taylor rule is active outside the ZLB, aggregate supply effects tend to dampen the increase in real rates and thus limit the crowding out of private consumption. Coupled with a higher level of natural consumption tomorrow, productive government spending induces higher multipliers than in the standard case.

As this discussion has made clear, results depend crucially on how (dis)inflationary the fiscal stimulus is. In fact, most of the literature on the ZLB has emphasized the role of real interest rates. While our benchmark calibration is in line with some of the empirical evidence, higher values for $\psi=40$ cannot be ruled out (see e.g. the discussion in Erceg \& Lindé (2010) and the references therein). Since $\psi$ indexes price rigidity, a higher value for this parameter will imply a lower $\frac{\partial \pi_{t}}{\partial m c_{t}}$. With inflation reacting less on impact, we expect that the gap between multipliers for different composition of the fiscal package will shrink. In Figure 2, we report the results of our preferred ARRA specification and the standard multiplier for both $\psi=40$ and $\psi=90$. The case $\psi=90$ corresponds to an average duration of prices of 4 quarters ${ }^{5}$ or a Calvo probability of 0.75, as in Taylor (1999).

\footnotetext{
${ }^{5}$ The result are similar when considering a Calvo parameter of 0.9 , which implies an average duration of prices of 10 quarters and a price rigidity parameter $\psi=650$.
} 

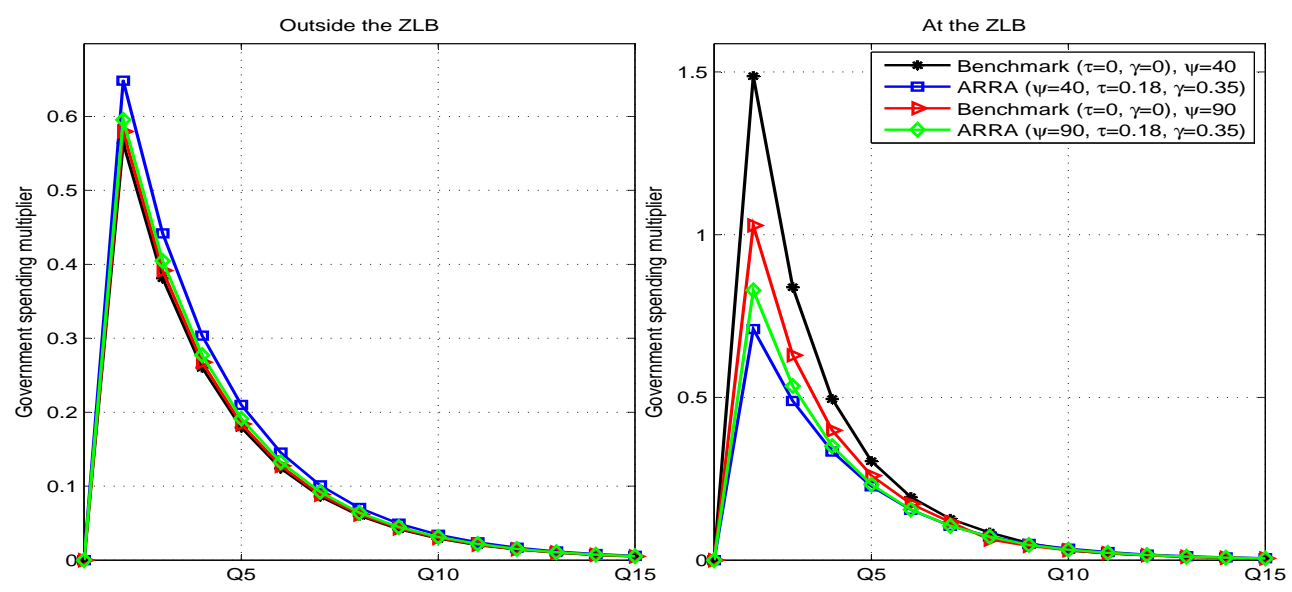

Figure 2: Government spending multiplier.

In line with the intuition, the composition of government spending induces a lower gap between the multipliers. This shows in the case where the economy is outside the ZLB. At the ZLB however, some differences remain. In the standard case, higher price rigidity induces lower inflation on impact and thus a lower multiplier. In the ARRA specification, higher price rigidity induces less deflation so that the multiplier actually increases.

In summary, for the stimulative effects of government spending to be maximal at the ZLB, government spending should be both non-substitutable with private consumption and wasteful. This was surely not the case with the American Recovery and Reinvestment Act of 2009, which included productive and substitutable government spending as well. Our simulations indicate that its effects were not likely to be much larger than in normal times, with output increasing less than government spending.

\section{Conclusion}

We show that the multiplier at the ZLB may substantially vary, depending on whether the government spending is productive, substitutable or not with consumption. It lies between -0.25 and +1.5 according to the different specifications. It highlights that the modeling of government spending has important implications for the policy analysis. The assumptions made about the structure of government spending should be carefully considered. The estimation of a more micro-founded DSGE model should be conducted for future research to determine the right structure of government spending. 


\section{References}

Barro, R. J. (1990). Government spending in a simple model of endogenous growth. Journal of Political Economy, 98(5), S103-26.

Bouakez, H. \& Guillard, M. (2013). Government spending and the zero bound on interest rates in a small open economy. Mimeo.

Christiano, L., Eichenbaum, M., \& Rebelo, S. (2011). When is the government spending multiplier large? Journal of Political Economy, 119(1), 78 - 121.

Cogan, J. F., Cwik, T., Taylor, J. B., \& Wieland, V. (2010). New keynesian versus old keynesian government spending multipliers. Journal of Economic Dynamics and Control, 34(3), 281-295.

Eggertsson, G. B. (2011). What fiscal policy is effective at zero interest rates? In NBER Macroeconomics Annual 2010, Volume 25, NBER Chapters (pp. 59-112). National Bureau of Economic Research, Inc.

Erceg, C. \& Lindé, J. (2010). Is There a Fiscal Free Lunch in a Liquidity Trap? CEPR Discussion Papers 7624, C.E.P.R. Discussion Papers.

Fernández-Villaverde, J., Gordon, G., Guerrón-Quintana, P., \& Rubio-Ramírez, J. F. (2012). Nonlinear adventures at the zero lower bound. Working Papers 12-10, Federal Reserve Bank of Philadelphia.

Krause, M. U. \& Lubik, T. A. (2007). The (ir)relevance of real wage rigidity in the new keynesian model with search frictions. Journal of Monetary Economics, 54(3), 706-727.

Linnemann, L. \& Schabert, A. (2006). Productive government expenditure in monetary business cycle models. Scottish Journal of Political Economy, 53(1), $28-46$.

Roulleau-Pasdeloup, J. (2013). The productive government spending multiplier, in and out of the zero lower bound. CREST working paper $n^{\circ} 2013-02$.

Taylor, J. B. (1999). Staggered price and wage setting in macroeconomics. In J. B. Taylor \& M. Woodford (Eds.), Handbook of Macroeconomics, volume 1 of Handbook of Macroeconomics chapter 15, (pp. 1009-1050). Elsevier. 


\section{SFB 649 Discussion Paper Series 2014}

For a complete list of Discussion Papers published by the SFB 649, please visit http://sfb649.wiwi.hu-berlin.de.

001 "Principal Component Analysis in an Asymmetric Norm" by Ngoc Mai Tran, Maria Osipenko and Wolfgang Karl Härdle, January 2014.

002 "A Simultaneous Confidence Corridor for Varying Coefficient Regression with Sparse Functional Data" by Lijie Gu, Li Wang, Wolfgang Karl Härdle and Lijian Yang, January 2014.

003 "An Extended Single Index Model with Missing Response at Random" by Qihua Wang, Tao Zhang, Wolfgang Karl Härdle, January 2014.

004 "Structural Vector Autoregressive Analysis in a Data Rich Environment: A Survey" by Helmut Lütkepohl, January 2014.

005 "Functional stable limit theorems for efficient spectral covolatility estimators" by Randolf Altmeyer and Markus Bibinger, January 2014.

006 "A consistent two-factor model for pricing temperature derivatives" by Andreas Groll, Brenda López-Cabrera and Thilo Meyer-Brandis, January 2014.

007 "Confidence Bands for Impulse Responses: Bonferroni versus Wald" by Helmut Lütkepohl, Anna Staszewska-Bystrova and Peter Winker, January 2014.

008 "Simultaneous Confidence Corridors and Variable Selection for Generalized Additive Models" by Shuzhuan Zheng, Rong Liu, Lijian Yang and Wolfgang Karl Härdle, January 2014.

009 "Structural Vector Autoregressions: Checking Identifying Long-run Restrictions via Heteroskedasticity" by Helmut Lütkepohl and Anton Velinov, January 2014.

010 "Efficient Iterative Maximum Likelihood Estimation of HighParameterized Time Series Models" by Nikolaus Hautsch, Ostap Okhrin and Alexander Ristig, January 2014.

011 "Fiscal Devaluation in a Monetary Union" by Philipp Engler, Giovanni Ganelli, Juha Tervala and Simon Voigts, January 2014.

012 "Nonparametric Estimates for Conditional Quantiles of Time Series" by Jürgen Franke, Peter Mwita and Weining Wang, January 2014.

013 "Product Market Deregulation and Employment Outcomes: Evidence from the German Retail Sector" by Charlotte Senftleben-König, January 2014.

014 "Estimation procedures for exchangeable Marshall copulas with hydrological application" by Fabrizio Durante and Ostap Okhrin, January 2014.

015 "Ladislaus von Bortkiewicz - statistician, economist, and a European intellectual" by Wolfgang Karl Härdle and Annette B. Vogt, February 2014.

016 "An Application of Principal Component Analysis on Multivariate TimeStationary Spatio-Temporal Data" by Stephan Stahlschmidt, Wolfgang Karl Härdle and Helmut Thome, February 2014.

017 "The composition of government spending and the multiplier at the Zero Lower Bound" by Julien Albertini, Arthur Poirier and Jordan RoulleauPasdeloup, February 2014.

\section{SFB 649, Spandauer Straße 1, D-10178 Berlin} http://sfb649.wiwi.hu-berlin.de

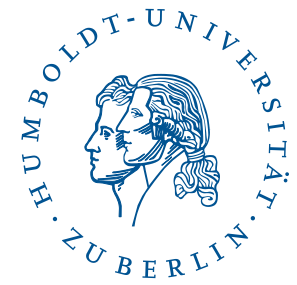

